\title{
Adaptation or Manipulation? Unpacking Climate Change Response Strategies
}

$\underline{\text { Dana C. Thomsen }}^{1}, \underline{\text { Timothy F. Smith }}^{1}$, and Noni Keys ${ }^{1}$

\begin{abstract}
Adaptation is a key feature of sustainable social-ecological systems. As societies traverse various temporal and spatial scales, they are exposed to differing contexts and precursors for adaptation. A cursory view of the response to these differing contexts and precursors suggests the particular ability of persistent societies to adapt to changing circumstances. Yet a closer examination into the meaning of adaptation and its relationship to concepts of resilience, vulnerability, and sustainability illustrates that, in many cases, societies actually manipulate their social-ecological contexts rather than adapt to them. It could be argued that manipulative behaviors are a subset of a broader suite of adaptive behaviors; however, this paper suggests that manipulative behaviors have fundamentally different intentions and outcomes. Specifically, adaptive behaviors are respectful of the intrinsic integrity of social-ecological systems and change is directed toward internal or self-regulating modification. By way of contrast, manipulative behaviors tend to disregard the integrity of social-ecological systems and focus on external change or manipulating the broader system with the aim of making self-regulation unnecessary. It is argued that adaptive behaviors represent long-term strategies for building resilience, whereas manipulative behaviors represent short-term strategies with uncertain consequences for resilience, vulnerability, and the sustainability of social-ecological systems. Of greatest significance; however, is that manipulative strategies have the potential to avoid authentic experiences of system dynamics, obscure valuable learning opportunities, create adverse path dependencies, and lessen the likelihood of effective adaptation in future contexts.
\end{abstract}

Key Words: adaptation, adaptive capacity, climate change, learning, manipulation, path dependency, resilience

\section{INTRODUCTION}

Adaptation is a recent and increasing focus for research and policy concerned with responding to the unavoidable impacts of climate change (Adger et al. 2007). In the late 1990s, Smit et al. $(1999,2000)$ began to critique the meaning of adaption in relation to climate change by asking: (i) adaptation to what; (ii) who or what adapts; and (iii) how does adaptation occur? This line of questioning provided an avenue for evaluating the merits of adaptation beyond the needs and experiences of those seeking change toward a much broader exploration of impacts at the system level. It also allows for consideration of the values and ethics associated with adaptation toward sustainable societal processes and aspirations. This is consistent with recommendations for a greater focus on adaptations that support sustainable development in the Fourth Assessment Report of the Intergovernmental Panel on Climate Change (Adger et al. 2007) and indicates that the critique of Smit and colleagues has yet to influence adaptation policy, and that the clarity that answering such questions could have achieved is yet to emerge. For example, a review of major international reports such as those by the Intergovernmental Panel on Climate Change (IPCC) and the United Nations Framework Convention on Climate Change (UNFCCC) and publications in journals including Nature and Science revealed that use of the term "adaptation" is still gaining currency, and a consensus definition has yet to be defined (Levina and Tirpak 2006). In particular, studies concerning the social and ethical dimensions of adaptation are just beginning to emerge (e.g., Adger 2009, Jones and Boyd 2011).
Nevertheless, societal adaptation to a range of stressors is a prevalent and defining feature of persistent societies (e.g., Bussey et al. 2011). Research in traditional disciplines such as archeology (e.g., Morrison 2006) and interdisciplinary fields such as resilience (e.g., Gunderson and Holling 2002) illustrates that adaptation to changing social-ecological systems, including climatic variables, is not a recent attribute of human societies. However, recognition of "dangerous" climate change and the scale and severity of the impacts now experienced and predicted is novel and creates added impetus to focus on adaptation efforts (Adger et al. 2007). Furthermore, Adger et al. (2007) highlight that multi-sectoral assessments of the costs and benefits of adaptation at the global scale are limited. Hence, in a globalized world, how should adaptation efforts be judged? Which parameters should guide our approaches? Is adapting to climate change enough, or will this singular focus ultimately undermine the systems that sustain life?

Literature to inform societal response to climate change comes primarily from three different, but often overlapping, discourses: vulnerability, resilience, and sustainability (Turner 2010). The contributions of these discourses to global issues that concern social and ecological interactions, such as climate change, have been demonstrated in detail elsewhere (e.g., Adger 2006, Folke 2006, Kates et al. 2001). The similarities among these discourses suggest that there is potential for the integration of vulnerability and resilience within the broader context of sustainability (Adger 2006, 
Turner 2010). Such integration allows a more critical view of adaptation that takes into account the multifaceted drivers, intentions, and impacts of adaptation. Significantly, the simultaneous consideration of vulnerability, resilience, and sustainability provides an opportunity to consider adaptation in a broader cross-sectoral, and potentially cross-scale, context. It also allows the examination of outcomes of adaptation at the system level rather than as a response to a particular issue. By framing adaptation in this way, it may be possible to avoid unsustainable "adaptation" pathways, such as energy-intensive heating and cooling of dwellings (Adger et al. 2007, Hallegatte 2009).

An example of the broader range of considerations provided by the integration of these discourses can be found in the most recent notions of resilience. With origins in ecological theory and grounded in assumptions regarding the stability of systems, resilience has evolved to encompass human dimensions and more dynamic conceptions of system states (Folke 2006). The most recent definitions do not imply a "return to equilibrium" and instead focus on the ability of systems to transition to alternative states (Duit et al. 2010). Not only does this broader and more dynamic focus involve consideration of social dimensions, such as the role of power and issues of social justice more commonly associated with sustainability discourses, the acceptance of systems transitioning from one state to another provides an opportunity for normative discussions around desirable and undesirable system states (Nelson et al. 2007, Duit et al. 2010). Of significance to adaptation, the focus on transition and desirable system states challenges the validity of the status quo and highlights the need to ensure that proposed initiatives do not further entrench existing inequalities or unsustainable practices and exacerbate processes of dangerous climate change. As Adger et al. (2009) highlight, it is necessary to be aware of underlying values and interests at both individual and societal levels before undertaking adaptation initiatives.

In this article, which is a starting point for further investigations, we draw on the integration of these discourses and earlier analyses of adaptation to discuss: (i) the intentions underlying adaptation; (ii) the focus of adaptation strategies; and (iii) the implications of adaptation at the system level. As this requires a broad theoretical frame, combined with the recognition of complex social-ecological considerations, our approach is also informed by the tenets of systems thinking (Senge 2006). We begin by providing a brief history of adaptation and its relationship to vulnerability, resilience, and sustainability. We then examine three main types of "adaptation" available to communities in the coastal zone to reveal contrasting perceptions of natural system states, differences in who or what adapts, and the implications for system resilience. In so doing, we suggest "manipulation" as an additional theoretical lens with which to more accurately analyze the range of contemporary adaptation responses.

\section{A BRIEF HISTORY AND CRITIQUE OF ADAPTATION}

Adaptation concepts originate from a range of disciplines with differing foci and implications for societal processes and outcomes. For example, Smit et al. (1999) highlight the various origins of adaptation in fields such as ecology, natural hazards, and risk management, and Head (2010) cites its established presence in cultural ecology. Orlove (2009) traces changes in the use of the term and observed that 17th century definitions of adaptation in the English language indicated a process of change, including connotations of "fitting in" or "suiting to" in reference to an external issue. From the mid-19th century, he noted more specific uses in science. For example, in 1859, Charles Darwin used the term to describe how organisms and species become progressively more suited to their environment. In particular, John Dewey (1916) drew on Darwin's description of adaptation to explain how individuals and societies could respond to or modify contexts toward social change and the realization of full potential. Orlove (2009) highlights that Dewey's definition has led to the common use of the term to describe a person's ability to adjust to dynamic contexts. Of relevance to climate change, the Intergovernmental Panel on Climate Change (IPCC) defines adaptation in the Third Assessment Report as "adjustment in natural or human systems in response to actual or expected climatic stimuli or their effects, which moderates harm or exploits beneficial opportunities" (McCarthy et al. 2001:982).

In the climate change context, the framework of Smit et al. $(1999,2000)$ provides an opportunity to clarify the meaning of adaptation-through exploring the intentions, the actors, and the nature and extent of processes and impacts. This framework appears to be an instrumental first step in preparing an adaptation strategy cognizant of the spatial, temporal, and developmental dimensions crucial for sustainability. The importance of these considerations in thinking more broadly about adaptation is reinforced by Adger et al. (2005), who focused on the intentions and impacts of adaptation across scales to highlight the importance of effectiveness, efficiency, equity, and legitimacy in assessing adaptation outcomes. Similarly, Nelson et al. (2007) highlight that adaptation refers to the conceptual decision-making processes and subsequent actions taken to address the impacts of change. Nevertheless, most emphasis in public policy debates has been placed on taking action, with limited emphasis on equitable decisionmaking processes or the nature and scale of the impacts of adaptation. Adaptation is most often presented as an array of adaptation options in a shopping-list style (e.g., air conditioning, desalinization, insurance, relocation, sea walls), where people are asked to choose among a selection of alternative policies, practices, and/or technologies without deeper consideration of the broader or systemic implications.

We argue that there is a disjuncture, and an opportunity for an entirely different focus for adaptation, between the initial and 
Darwinian uses of the term and more recent connotations. Drawing on the analytical frameworks of Smit et al. (1999, 2000) and Adger et al. (2005, 2009), we suggest that the key difference lies in the intention and focus of adaptation. Darwinian conceptions of adaptation as "fitting in" suggest self-directed change with the intent of internal modification to better suit external contexts (i.e., "adaptation to"). Conceptions of adaptation commonly presented in contemporary climate change adaptation literature, however, also allow for options that modify external contexts, permitting externally directed change to better suit the existing predisposition of certain individuals or social groupings with the intention of avoiding change within these entities (i.e., "adaptation of"). Thus, contemporary definitions, which result in "adaptation of," may be more accurately described as manipulation and have the potential to negate the need for individuals or social groupings to "fit in" (in the short term) and, in many ways, represent Darwin's theory in reverse. To ensure adaptation efforts are more likely to be sustainable and cognizant of broader social-ecological contexts, we argue that it is important to direct discussions from the external focus of how "life should be" (Duit et al. 2010) to more internally focused discussions of how "should we behave."

\section{MANIPULATION}

Manipulation noun 1. The action of manipulating something in a skilful manner. 2.The action of manipulating someone in a clever or unscrupulous way.

Manipulate verb 1. Handle or control in a skilful manner (a tool, mechanism, information, etc.) in a skilful manner. 2. Control or influence (a person or situation) cleverly or unscrupulously. Oxford University Press (2011)

Definitions of "manipulation" and "manipulate" highlight that the main mechanism underpinning manipulation strategies is control of external system elements (i.e., other people or contexts) with the implicit intention of achieving outcomes desired by the manipulator. This approach is likely to be effective, at least from the perspective of the manipulator, in the short term. However, the act of manipulation (with often a single desired outcome) may not recognize the interdependencies inherent in complex social-ecological systems and may lead to an inability to achieve those desired outcomes into the future-through reduced opportunities for authentic learning experiences.

Understanding of complex systems is not well developed (e. g., Underdal 2010) and is likely to remain so into the foreseeable future (Owens 2010), therefore, the actual direct and indirect consequences (i.e., predictability) of adaptation and manipulation initiatives remain difficult to determine over the extended time scales required by sustainability. Certainly, complexity is inherent when dealing with a range of sustainability challenges; nevertheless, examining the intended focus of actions (i.e., who or what adapts) can help in understanding the potential for a range of both positive and negative system impacts.

Manipulation through externally directed interventions reflects a reductionist approach as it separates system elements from one another and disconnects those initiating interventions from the systems they are attempting to influence, leading to defensive rather than reflective management strategies (Senge 2006, Smith 2009). Senge (2006) argues that reductionist processes are established early in western learning approaches and make it difficult to see the connections between actions and effects, or the nature and extent of interventions and outcomes. Predictability of outcomes aside, the main mechanism by which manipulative strategies undermine sustainable futures is by limiting adaptive learning (see Smith and Smith 2006, Smith et al. 2009) opportunities through the avoidance of authentic experiences of system dynamics (i.e., social-ecological change). Indeed, the underlying assumption of control over a system or, at least, part of a system may not be explicit in such decision-making processes and has the potential to limit imaginative abilities (Senge 2006). The negative impact of this on adaptation and adaptive capacity is demonstrated in a recent study of past adaptations that found imaginative resources to be a significant determining factor in the success or failure of past societies (Bussey et al. 2011).

Adaptation and manipulation strategies are generally dynamic and continuous in some form-being shaped by a series of adaptive or manipulative actions over time. When viewed from a systems perspective, a manipulation trajectory increases social-ecological stress and decreases the capacity to adapt over time (Fig. 1), leading to the heightened potential for system collapse. These influences on the system being manipulated and the ability to adapt may also create manipulation path dependencies, whereby each manipulative action increases social-ecological stress, reduces adaptive capacity, and necessitates continued manipulative actions in order to avoid changing the dominant social paradigm. This need for continued response is primarily driven by the desire to maintain a system state, rather than adapt to system dynamics. Furthermore, a manipulation pathway enhances the potential for additional negative feedback loops, where manipulation increases at the expense of learning and adaptation. This, in turn, further diminishes adaptive capacity through the inability to develop transformative learning skills.

The combination of externally directed change, skilled actors, narrowly conceived systems scope, and limited adaptive learning appears a potent mix, with significant potential for unsustainable processes and outcomes that increase vulnerability and decrease resilience. In this way, manipulative actions may be categorized as "short-term fixes" 
(Senge 2006) that address symptoms rather than causes such that issues keep reoccurring or are exacerbated.

Fig. 1. Relationship among manipulation, adaptive capacity, and social-ecological stress.

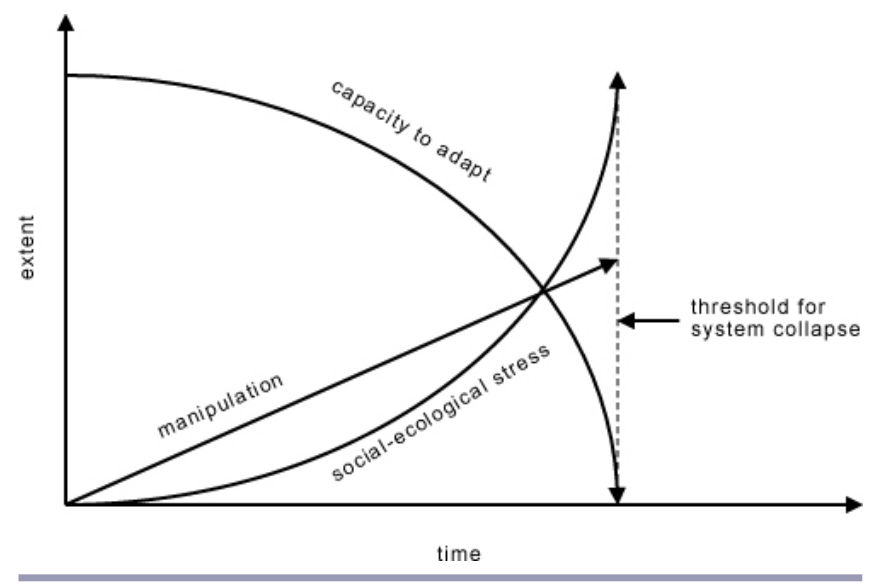

\section{Manipulation and Maladaptation}

Understanding the intention of proposed adaptations and the scale of impacts has important implications for judging the success of adaptation initiatives (Adger et al. 2005) and for distinguishing manipulation from maladaptation. As adaptation outcomes traverse spatial and temporal boundaries they may become less relevant, ineffective or even inappropriate (Adger et al. 2005). In the third assessment report, the IPCC defined such inappropriate outcomes as maladaptation. Specifically, the IPCC defined maladaptation as "any changes in natural or human systems that inadvertently increase vulnerability to climatic stimuli; an adaptation that does not succeed in reducing vulnerability but increases it instead" (McCarthy et al. 2001:990). In the context of climate change, Barnett and O'Neill (2010) indicate that references to maladaptation began to occur in the literature in the early 1990s and cover a range of sectors and various geographic and temporal scales. They describe five distinct types of maladaptation to climate change, including options that, to varying degrees, increase emissions, unfairly burden vulnerable communities, have high opportunity costs, decrease adaptation incentives, and result in path dependencies that limit options for future generations (Barnett and O'Neill 2010). At first glance, such maladaptations appear synonymous with manipulation. However, all maladaptations commence as adaptations and are deemed unintentional in "inadvertently" increasing vulnerability. Consequently, a fundamental difference between manipulation and maladaptation relates to intent-whereby an intention to adapt that leads to adverse consequences can be defined as maladaptation; however, where there is no intention to adapt (i.e., undertake internal regulation), then we argue that such actions are better defined as manipulation.

\section{ADAPTATION AND MANIPULATION IN COASTAL SYSTEMS}

To illustrate the contrasting intentions, initiatives, and outcomes of adaptation and manipulation, we review climate change response strategies in coastal systems. The coastal zone has been selected to explore the manipulation concept in more detail, as coastal zones are particularly dynamic and transitional systems that support significant and increasing human populations and associated infrastructure (Nicholls et al. 2007). Coastal zones are also particularly vulnerable to the impacts of climate change (e.g., sea-level rise and storm surge) that are likely to reduce the timescale once anticipated for transitional processes in these systems. As Hopkins et al. (2011) highlight, local coastal zones provide a microcosm of larger scale and stressed complex systems. Therefore, analysis of human-environment interactions in the coastal zone provides an instructive account of the transitions likely to be experienced in other communities over much reduced temporal and spatial scales.

The following analysis of adaptation options and practices in the coastal zone is used to examine perceptions of "natural" system states, who or what adapts, and general trends in adaptation in order to explore the manipulation concept and the implications for resilience in context rather than as an empirical test. Adaptation options available to coastal communities can be broadly classified as "protect," "accommodate," or "retreat," following the report of the Coastal Zone Management Subgroup (CZMS) within the First Assessment Report of the IPCC (Misdorp et al. 1990). A more recent review of how these have evolved illustrates that protect options remain largely defensive-being represented by phrases such as "advance the line" or "hold the line" and include hard (e.g., sea walls and groynes) and/or soft (e.g., dune rehabilitation) interventions (Nicholls et al. 2007). Accommodate options seek to increase the flexibility of coastal communities so they may cope with change and continue using the land through interventions, such as anticipatory building codes or insurance (CZMS 1990). Retreat options involve the movement of people and associated infrastructure away from coastal areas into less exposed areas, with significant potential for the long-term resilience of communities. However, retreat also has significant potential for disruption to communities, especially in nations with low levels of adaptive capacity (Nicholls et al. 2007). Nevertheless, as the resilience of coastal systems is increasingly being tested following repeated disasters, the costs of adaptation in vulnerable coastal communities are generally considered less than the costs of inaction (Nicholls et al. 2007). In particular, Klein et al. (2001) identified increased recognition of the advantages of soft protection, accommodate and retreat strategies, and the need for adaptations tailored to local social-ecological contexts. The review of Klein et al. (2001) suggests the need for coastal areas to transition from hard protective strategies toward the 
accommodate and retreat end of the adaptation spectrum. Indeed, protect and accommodate options are well established in many coastal areas. Retreat, however, although on the agenda for particularly vulnerable coastal communities, is only just beginning to be considered more widely. The following case study of Noosa Main Beach is presented to offer an insight into the mechanisms underpinning transition between adaptation options.

\section{Noosa Main Beach, Queensland, Australia}

Noosa Main Beach is an iconic tourist destination within Queensland, Australia and has been selected as a case study as it is a vulnerable coastal community located in South East Queensland, an area noted by the IPCC as particularly vulnerable to the impacts of climate change (Parry et al. 2007). In addition, Noosa has experienced several cycles of significant investment and infrastructure development, with strategies for the management of Main Beach transitioning from retreat and accommodate to protect.

Early in Noosa's history as a tourist destination, the types of development reflected a combination of the retreat and accommodate responses to the natural coastal processes experienced in all undeveloped beaches (e.g., cycles of erosion and deposition). For example, in the 1920s, there was minimal development of the coastline, with beach kiosks built on sleds so they could be moved inland during storms (Tomlinson 2002). Since this time, however, there has been substantial economic investment and an increase in the built environment consistent with that of the Australian coastline generallyover $85 \%$ of Australians live within $50 \mathrm{~km}$ of the coastline (Australian Bureau of Statistics 2004). The short-term perspective and misunderstanding or misrepresentation of the coastal zone associated with the intensification of such coastal development are highlighted by Tomlinson (2002), who noted that periods of coastal development often coincided with calmer weather conditions, with some developments being damaged or completely destroyed in later storms.

In Noosa, initial recognition of the coastline as a transitional system characterized by cycles of erosion, depletion, and deposition has been replaced with the preference for enduring sandy beaches of sufficient width to protect expensive coastal developments and maintain consistency with images depicted as part of tourism sales campaigns. Significant development within Noosa's coastal zone commenced in the mid 1960s and led to the installation of rock seawalls and groynes and training of the river mouth (Chamberlain and Tomlinson 2006). The subsequent development of the Main Beach fore dunes into the tourist precinct of Hastings Street has added further impetus for the ongoing use of a range of engineering works to maintain a static coastline that now includes beach nourishment (Smith et al. 2011). Approximately, 40,000 $\mathrm{m}^{3}$ of sand is pumped onto the beach each year (Chamberlain and Tomlinson 2006). In combination, these protective strategies have resulted in the development of a new system equilibrium and the need for ongoing beach management (Tomlinson 2002). This approach is consistent with the preference for engineered coastal protection works to protect private property along Australia's coastline generally (Thom 2004).

The situation in Noosa reflects that of much of the developed Australian coastline and reveals the dominant contemporary expectation of wide sandy beaches that alter little in width. As Tomlinson (2002:19) argues, "the community's perception of what is natural or desirable often is contrary to the reality of the system." To this end, actors in the social system dimension have progressively engaged in protective strategies and manipulated ecological system dimensions (e.g., through engineering works) to reduce exposure to storm surge and other processes of coastal erosion (Fig. 2). Changes have been imposed upon the ecological dimension by the social dimension to protect static perceptions of natural system state and associated socioeconomic investments. In this scenario, minimal disturbance is experienced within the social dimension of the system in the short to medium termdepending on the scale and frequency of climatic disturbance and the manipulative capacity of the community. However, the effects on other system elements may be significant and not apparent in the short term. For example, restrictions have been placed on dredging in some areas for beach nourishment by the Environmental Protection Agency due to concerns regarding fish habitat (Chamberlain and Tomlinson 2006).

Fig. 2. Response shift from adaptation to manipulation, Noosa Main Beach.

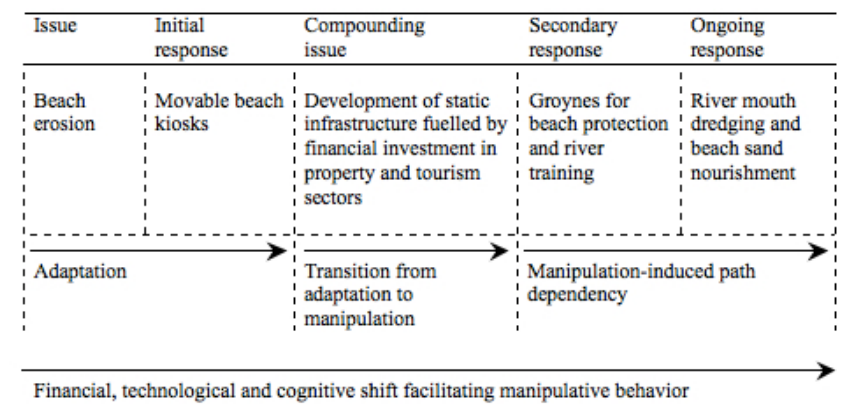

It is important to note that the case of Noosa is not unique and there are numerous examples of actions with the intent of modifying external system characteristics to achieve preferred anthropogenic system experiences in the short term. In fact, the case of Noosa Main Beach highlights that a range of strategies may exist for any given location, and manipulations occur even within communities that embrace sustainability principles and have a history of regulating development to be mindful of conservation and sustainability ideals. 
Table 1. Comparison of protect, accommodate, and retreat options

\begin{tabular}{|c|c|c|c|}
\hline "Adaptation" option & $\begin{array}{l}\text { Dominant perception of the "natural" } \\
\text { system state }\end{array}$ & $\begin{array}{l}\text { Who and what adapts to achieve desired } \\
\text { system state }\end{array}$ & Longer term implications for resilience \\
\hline Protect & $\begin{array}{l}\text { Static or minimal dynamism (e.g., } \\
\text { consistent sand coverage, stable river } \\
\text { entrances). }\end{array}$ & $\begin{array}{l}\text { The social dimension of the system } \\
\text { defends itself from change by } \\
\text { manipulating the ecological dimension, } \\
\text { often through a sociotechnical regime } \\
\text { (e.g., a reduction in exposure through } \\
\text { sand mining, beach wall, and/or groyne } \\
\text { construction). }\end{array}$ & $\begin{array}{l}\text { Significant ongoing management and } \\
\text { investment required, with the potential to } \\
\text { impact negatively upon other system } \\
\text { components. }\end{array}$ \\
\hline Accommodate & $\begin{array}{l}\text { Dynamic system including periods of } \\
\text { inundation and erosion with some } \\
\text { degree of predictability and perceived } \\
\text { high likelihood of system resilience. }\end{array}$ & $\begin{array}{l}\text { The social dimension of the system } \\
\text { reacts to or anticipates changes in the } \\
\text { ecological dimension and copes by } \\
\text { making adjustments in socioeconomic } \\
\text { and/or sociotechnical system } \\
\text { components (e.g., elevating buildings, } \\
\text { insurance). }\end{array}$ & $\begin{array}{l}\text { Resilience may be ensured in the short to } \\
\text { medium term, depending on the context, } \\
\text { the severity of climatic impacts, and the } \\
\text { adaptive capacity of local communities. } \\
\text { Longer term resilience is unlikely. }\end{array}$ \\
\hline Retreat & $\begin{array}{l}\text { Increasingly dynamic system including } \\
\text { less predictable disturbance regimes } \\
\text { and perceived negative impacts on } \\
\text { system resilience, particularly affecting } \\
\text { the social dimension. }\end{array}$ & $\begin{array}{l}\text { The social dimension of the system } \\
\text { adapts by reducing exposure to the } \\
\text { impacts of climate change through the } \\
\text { migration of communities and } \\
\text { associated infrastructure. }\end{array}$ & $\begin{array}{l}\text { Significant initial investment with } \\
\text { decreasing costs and increased resilience } \\
\text { over time if issues associated with } \\
\text { migration are anticipated and resourced } \\
\text { (e.g., revised settlement patterns, } \\
\text { socioeconomic transition strategies, and } \\
\text { cultural needs assessment). }\end{array}$ \\
\hline
\end{tabular}

\section{DISCUSSION OF ADAPTATION AND MANIPULATION PATHWAYS}

Distinctions among the protect, accommodate, and retreat options according to dominant perception of natural system states, who or what adapts, and the implications for resilience (Table 1) indicate that protective strategies are driven by static perceptions of natural system states and externally directed, such that interventions are imposed upon other system components. As such, protective strategies may be better defined as manipulative rather than adaptive. Accommodate and retreat options, however, are based upon much more dynamic perceptions of natural system states and a much greater tendency to make changes to the social dimensions of systems. We argue that these internally directed strategies are more consistent with notions of adaptation as their intention to respond to dynamic external contexts is through internal regulation.

The relevance to coastal communities is that protect options based upon manipulative strategies are likely to be short term in effect, reduce the long-term resilience of social-ecological systems, and are expensive in the longer term. For example, hard protective structures can limit the impact upon socioeconomic systems in the short to medium term, but negatively impact upon ecological system components, such as salt marshes and wetlands, as these are progressively limited in extent or "squeezed" (e.g., Knogge et al. 2004, Nicholls et al. 2007).

Although intent can change over time, it is increasingly difficult to shift from manipulation to adaptation, rather than from adaptation to manipulation, due to path dependencies and influences on adaptive capacity. Similarly, as Smith and Stirling (2010) note, some sociotechnical systems become deeply embedded and self-reinforcing through such features as significant institutional and political support, economic significance, and integration within the broader social fabric of a particular locale. Significantly, manipulative strategies disconnect communities from system dynamics, lessen opportunities for learning about transitional systems in context, and have the potential to undermine adaptive capacity. Often, changes to ecological system components continue or intensify as interventions affect the overall system functionfrequently exacerbating the very processes they were meant to overcome (e.g., beach walls enhancing erosion) and creating unforeseen or additional vulnerabilities.

\section{CONCLUSION}

Adaptation and maladaptation are currently used to describe existing climate change response strategies. As a starting point for further investigation, we suggest manipulation as an additional and more critical lens for reflection on such strategies to facilitate a more accurate evaluation of resilience. Risks associated with manipulative strategies are underpinned by the tendency to limit or obscure opportunities for learning about transitional systems such that long-term adaptive capacity is reduced.

Literature and conversations around adaptation are often posed as if adaptation is an option that societies are considering. Yet, there is nothing to suggest that societies are at such a crossroads. Individuals, communities, and institutions make such decisions constantly and are most likely 
in the midst of an adaptation, maladaptation or manipulation cycle-cognizant of it or not. Furthermore, the example reviewed in this article suggests that once a path of manipulation begins then path dependency is likely, as the outcomes of manipulation tend to create a self-reinforcing cycle. The lure of manipulative approaches is highlighted through the case study of Noosa, where a path of adaptation was initially embarked upon through movable beach kiosks; however, with increasing development pressure and the desire to maintain a static natural environment, the response rapidly became a self-reinforcing activity of persistent manipulation. In addition, it is difficult to revert to a path of adaptation because of the engrained sociocultural norms and system expectations created. Indeed, with every manipulation, the actors are further removed from the system they are manipulating, and the concept of adaptation becomes increasingly unfamiliar and less tangible.

In summary, social-ecological systems are extremely complex and dynamic, and understanding of them is always likely to be limited (Owens 2010, Underdal 2010); therefore, we are unlikely to anticipate with accuracy over spatial, temporal, and cultural scales all of the impacts of our interventions. However, we can choose to respond to socialecological dynamics by making internal adjustments (i.e., adaptations) in human systems (at either individual or societal scales as appropriate) or external adjustments (i.e., manipulations). The external focus of manipulation (i.e., who or what changes) provides an essential distinction from adaptation. We argue that internal adjustments cognizant of both the social and ecological dimensions of social-ecological systems present much greater learning opportunities and prospects for building adaptive capacity and ensuring a sustainable future.

Responses to this article can be read online at: http://www.ecologyandsociety.org/voll7/iss3/art20/ responses/

\section{Acknowledgments:}

We are grateful for the helpful suggestions of two anonymous referees and the support of the CSIRO Flagship Collaboration Fund through the Coastal Collaboration Cluster and the South East Queensland Climate Adaptation Research Initiative.

\section{LITERATURE CITED}

Adger, W. N. 2006. Vulnerability. Global Environmental Change 16:268-281.

Adger, W. N., S. Agrawala, M. M. Q. Mirza, C. Conde, K. O'Brien, J. Pulhin, R. Pulwarty, B. Smit, and K. Takahashi. 2007. Assessment of adaptation practices, options, constraints and capacity. Pages 717-743 in M. L. Parry, O. F. Canziani,
J. P. Palutikof, P. J. van der Linden, and C. E. Hanson, editors. Climate Change 2007: impacts, adaptation and vulnerability. Contribution of Working Group II to the Fourth Assessment Report of the Intergovernmental Panel on Climate Change. Cambridge University Press, Cambridge, UK.

Adger, W. N., N. Arnett, and E. Tompkins. 2005. Successful adaptation to climate change across scales. Global Environmental Change 15:77-86. http://dx.doi.org/http://dx.doi. org/10.1016/j.gloenvcha.2004.12.005

Adger, W. N., S. Dessai, M. Goulden, M. Hulme, I. Lorenzoni, D. Nelson, L. Naess, J. Wolf, and A. Wreford. 2009. Are there social limits to adaptation to climate change? Climatic Change 93(3):335-354. http://dx.doi.org/http://dx.doi.org/10.1007/s1 0584-008-9520-Z

Australian Bureau of Statistics. 2004. Year Book Australia. Australian Government, Canberra, Australia. [online] URL: http://www.abs.gov.au/AUSSTATS/abs@.nsf/ allprimarymainfeatures/08CECF3FD75BF9CBCA2570A7000A22F0? opendocument

Barnett, J., and S. O'Neill. 2010. Maladaptation. Global Environmental Change 20:211-213. http://dx.doi.org/http://dx. doi.org/10.1016/j.gloenvcha.2009.11.004

Bussey, M., R. W. Carter, N. Keys, J. Carter, R. Mangoyana, J. Matthews, D. Nash, J. Oliver, R. Richards, A. Roiko, M. Sano, D. C. Thomsen, E. Weber, and T. F. Smith. 2011. Framing adaptive capacity through a history-futures lens: lessons from the South East Queensland Climate Adaptation Research Initiative. Futures 44(4):385-397. http://dx.doi.org/ http://dx.doi.org/10.1016/j.futures.2011.12.002

Chamberlain, S., and R. Tomlinson. 2006. Noosa River entrance channel dynamics. Technical Report 61. Cooperative Research Centre for Coastal Zone, Estuary and Waterway Management. Indooroopilly, Queensland, Australia.

Darwin, C. 1859. On the origin of the species by natural selection. John Murray, London, UK.

Dewey, J. 1916. Democracy and education. Macmillan, New York, New York, USA.

Duit, A., V. Galaz, K. Eckerberg, and J. Ebbesson. 2010. Governance, complexity and resilience. Global Environmental Change 20:363-368. http://dx.doi.org/http://dx.doi.org/10.1016/ j.gloenvcha.2010.04.006

Folke, C. 2006. Resilience: the emergence of a perspective for social-ecological systems analyses. Global Environmental Change 16:253-267. http://dx.doi.org/10.1016/j.gloenvcha.2 $\underline{006.04 .002}$

Gunderson, L. H., and C. S. Holling. 2002. Panarchyunderstanding transformations in systems of humans and nature. Island Press, Washington, D.C., USA. 
Hallegatte, S. 2009. Strategies to adapt to an uncertain climate change. Global Environmental Change 19:240-247. http://dx. doi.org/10.1016/j.gloenvcha.2008.12.003

Head, L. 2010. Cultural ecology: adaptation-retrofitting a concept? Progress in Human Geography 34:234-242. http://d x.doi.org/http://dx.doi.org/10.1177/0309132509338978

Hopkins , T. S., D. Bailly, and J. G. Støttrup. 2011. A systems approach framework for coastal zones. Ecology and Society 16(4): 25. http://dx.doi.org/10.5751/ES-04553-160425 http:// dx.doi.org/10.5751/ES-04553-160425

Jones, L., and E. Boyd. 2011. Exploring social barriers to adaptation: insights from western Nepal. Global Environmental Change (2011), doi:10.1016/j.gloenvcha.2011.06.002 http://d x.doi.org/10.1016/j.gloenvcha.2011.06.002

Kates, R. W., W. C. Clark, R. Corell, J. M. Hall, C. C. Jaeger, I. Lowe, J. J. McCarthy, H. J. Schellnhuber, B. Bolin, N. M. Dickson, S. Faucheux, G. C. Gallopin, A. Grübler, B. Huntley, J. Jäger, N. S. Jodha, R. E. Kasperson, A. Mabogunje, P. Matson, H. Mooney, B. Moore, T. O'Riordan, and U. Svedin. 2001. Sustainability science. Science 292(5517):641-642.

Klein, R. J. T., R. J. Nicholls, S. Ragoonaden, M. Capobianco, J. Aston, and E. N. Buckley. 2001. Technological options for adaptation to climate change in coastal zones. Journal of Coastal Research 17(3):531-543.

Knogge, T., M. Schirmer, and B. Schuchardt. 2004. Landscape-scale socio-economics of sea-level rise. Ibis 146:11-17.

Levina, E., and D. Tirpak. 2006. Key adaptation concepts and terms. OECD/IEA Project for the Annex I Expert Group on the UNFCCC, Organisation for Economic Co-operation and Development, Paris, France.

McCarthy, J. J., O. F. Canziani, N. A. Leary, D. J. Dokken, and K. S. White, editors. 2001. Climate change 2001: impacts, adaptation, and vulnerability. Contribution of Working Group II to the Third Assessment Report of the Intergovernmental Panel on Climate Change, Cambridge University Press, Cambridge, UK.

Misdorp, R., J. Dronkers, and J. R. Spradley, editors. 1990. Intergovernmental Panel on Climate Change, Coastal Zone Management Systems: strategies for adaption to sea level rise. Intergovernmental Panel on Climate Change/Ministry of Transport and Public Works, The Hague, The Netherlands.

Morrison, K. D. 2006. Archaeology: failure and how to avoid it. Nature 440:752-754. http://dx.doi.org/10.1038/440752a

Nelson, D. R., W. N. Adger, and K. Brown. 2007. Adaptation to environmental change: contributions of a resilience framework. Annual Review of Environment and Resources 32:395-419. http://dx.doi.org/10.1146/annurev.energy.32.051 $\underline{807.090348}$
Nicholls, R. J., P. P. Wong, V. R. Burkett, J. O. Codignotto, J.E. Hay, R. F. McLean, S. Ragoonaden, and C. D. Woodroffe. 2007. Coastal systems and low-lying areas. Pages 315-356 in M. L. Parry, O. F. Canziani, J. P. Palutikof, P. J. van der Linden and C. E. Hanson, editors.Climate change 2007: impacts, adaptation and vulnerability. Contribution of Working Group II to the Fourth Assessment Report of the Intergovernmental Panel on Climate Change, Cambridge University Press, Cambridge, UK.

Orlove, B. 2009. The past, the present and some possible futures of adaptation. Pages 131-163 in W. N. Adger, I. Lorenzoni, and K. L. O'Brien, editors. Adapting to climate change: thresholds, values, governance. Cambridge University Press, Cambridge, UK. http://dx.doi.org/10.1017/C BO9780511596667.010

Oxford University Press. 2011. Oxford dictionaries. [online] URL: http://oxforddictionaries.com/definition/english/manipulate

Owens, S. 2010. Learning across levels of governance: expert advice and the adoption of carbon dioxide emissions reduction targets in the UK. Global Environmental Change 20:394-401. http://dx.doi.org/10.1016/j.gloenvcha.2009.11.001

Parry, M. L., O. F. Canziani, J. P. Palutikof, and coauthors. 2007. Technical summary. Pages 23-78 in M. L. Parry, O. F. Canziani, J. P. Palutikof, P. J. van der Linden and C. E. Hanson, editors.Climate change 2007: impacts, adaptation and vulnerability. Contribution of Working Group II to the Fourth Assessment Report of the Intergovernmental Panel on Climate Change, Cambridge University Press, Cambridge, UK.

Senge, P. M. 2006. The fifth discipline, the art and practice of the learning organization. Doubleday, New York, New York, USA. http://dx.doi.org/10.1002/pfi.4170300510

Smit, B., I. Burton, R. Klein, and R. Street.1999. The science of adaptation: a framework for assessment. Mitigation and Adaptation Strategies for Global Change 4:199-213. http://d X.doi.org/10.1023/A:1009652531101

Smit, B., I. Burton, R. Klein, and J. Wandel. 2000. An anatomy of adaptation to climate change and variability. Climatic Change 45:223-251. http://dx.doi.org/10.1023/A:1005661622966

Smith, A., and A. Stirling. 2010. The politics of socialecological resilience and sustainable socio-technical transitions. Ecology and Society 15(1): 11. [online] URL: htt p://www.ecologyandsociety.org/vol15/iss1/art11/

Smith, T. F. 2009. Beyond knowledge: a neo-research approach to climate change adaptation. Pages 30-44 in J. Martin, M. Rogers, and C. Winter, editors. Climate change responses across regional Australia: social learning and adaptation. VURRN Press, Victoria, Australia. 
Smith, T. F., S. Myers, D. C. Thomsen, and J. Rosier. 2011. Integrated coastal zone management and planning. Pages 109121 in W. Gullett, C. Schofield, and J. Vince, editors. Marine resource management. LexisNexis Butterworths, Sydney, Australia.

Smith, T. F., and D. C. Smith. 2006. Institutionalising adaptive learning for coastal management. Pages 115-120 in N. Lazarow, R. Souter, R. Fearon, and S. Dovers, editors. Coastal management in Australia: key institutional and governance issues for coastal natural resource management and planning. CRC for Coastal Zone, Estuary and Waterway Management, Brisbane, Australia.

Smith, T. F., D. C. Thomsen, R. W. Carter, G. Mayes, M. Nursey-Bray, G. Whisson, R. Jones, S. Dovers, and K. O'Toole. 2009. Enhancing science impact in the coastal zone through adaptive learning. Journal of Coastal Research Special Issue 56:1306-1310.

Thom, B. 2004. Geography, planning and the law: a coastal perspective. Australian Geographer 35:3-16. http://dx.doi.or $\mathrm{g} / 10.1080 / 0004918024000193694$

Tomlinson, R. 2002. Beaches our asset: planning and management for natural variability on open coastlines. Pages 7-33 in J. Piorewicz, editor. Proceedings of the public workshop "Beach protection: risk and management." Central Queensland University Press, Yeppoon, Queensland, Australia.

Turner, B. L. 2010. Vulnerability and resilience: coalescing or paralleling approaches for sustainability science? Global Environmental Change 20:570-576. http://dx.doi.org/http://dx. doi.org/10.1016/j.gloenvcha.2010.07.003

Underdal, A. 2010. Complexity and challenges of long-term environmental governance. Global Environmental Change 20:386-393. http://dx.doi.org/10.1016/j.gloenvcha.2010.02.005 